\title{
Research Paper: Combined Effect of Noise and Smoking ๑|॥ on the Cognitive Performance of Automotive Industry Workers
}

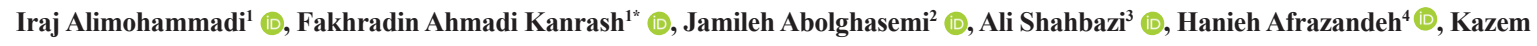
Rahmani $^{5}$ (D)

1. Department of Occupational Health Engineering, School of Public Health, Iran University of Medical Sciences, Tehran, Iran.

2. Department of Biostatistics, School of Public Health, Iran University of Medical Sciences, Tehran, Iran.

3. Department of Neuroscience, Faculty of Advanced Technologies in Medicine, Iran University of Medical Sciences, Tehran, Iran

4. Department of Internal Medicine, School of Medicine, Mashhad University of Medical Sciences, Mashhad, Iran.

5. Department of Epidemiology and Biostatistics, School of Public Health, Iran University of Medical Sciences, Tehran, Iran.

\begin{tabular}{|c|c|}
\hline \multirow{3}{*}{$\begin{array}{l}\text { Use vour device to scan } \\
\text { and read the article online }\end{array}$} & \\
\hline & $\begin{array}{l}\text { Citation: Alimohammadi, I., Ahmadi Kanrash, F., Abolghasemi, J., Shahbazi, A., \& Afrazandeh, H. (2019). Combined Effect } \\
\text { of Noise and Smoking on the Cognitive Performance of Automotive Industry Workers. Basic and Clinical Neuroscience, 10(5), } \\
\text { 515-526. http://dx.doi.org/10.32598/bcn.10.5.513 }\end{array}$ \\
\hline & doil' http://dx.doi.org/10.32598/bcn.10.5.513 \\
\hline
\end{tabular}

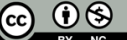

Article info:

Received: 26 Jun 2018

First Revision: 10 Jul 2018

Accepted: 27 Dec 2018

Available Online: 01 Sep 2019

Keywords:

Stroop test, Smoking, Noise, Occupational, Cognitive science

\section{AB S T RA C T}

Introduction: Noise is an environmental stressor and can cause or exacerbate mental disorders, and affect the individual performance in certain conditions. This study aimed to evaluate the combined effects of noise and smoking on the cognitive performance of the workers in the automotive industry.

Methods: This research is a descriptive-analytical study with a cross-sectional design conducted on 300 workers randomly assigned into two groups of noise-exposed and nonexposed. They were examined using computerized tests, including the Tower of London test (TOL), Continuous Performance test (CPT), and Stroop test. The sound pressure levels were measured based on an 8-hour equal-loudness contour in each group according to ISO 9612 standard, using the Testo CEL-815 sound level meter.

Results: The study of combined effects of noise and smoking on 12 CPT indicators using the 2-way Analysis of Variance (ANOVA) indicate that noise and smoking factors had a significant impact on the mean number of errors and correct responses in the third 50-stimuli stage, the mean number of errors and correct responses in the second 50-stimuli stage with $\mathrm{P}<0.001$, $\mathrm{P}<0.001, \mathrm{P}=0.012$ and $\mathrm{P}<0.001$ for smoking respectively, but only noise affected the other 7 indicators $(\mathrm{P}<0.001)$.

Conclusion: Smoking and noise have negative impacts on concentration, attention, and cognitive processing speed, which can lead to an individual's mistakes and delayed decision making at the workplace.

* Corresponding Author:

Fakhradin Ahmadi Kanrash, MSc.

Address: Department of Occupational Health Engineering, School of Public Health, Iran University of Medical Sciences, Tehran, Iran Tel: +98 (21) 86704749

E-mail:fahmadi1367@yahoo.com 


\section{Highlights}

- Brain function, cognitive processing speed, and individual performance are significantly lower in smokers compared to non-smokers.

- Noise and smoking have significant effects on cognitive performance indicators.

- High noise exposure is associated with the risk of an increased number of errors in responding to the test stimuli.

- Addiction to cigarettes and other nicotine-containing products harms cognitive performance, including executive functions.

\section{Plain Language Summary}

Excessive noise in industrial environments can cause hearing impairment, speech problems, sleep disorders, noise annoyance, and decreased efficiency of the workers. This study aimed to evaluate the combined effects of noise and smoking on the cognitive performance and psychological flexibility of workers in the automotive industry in Iran. The workers were assessed by proper tools to examine their mental performance and responses to low- or high-frequency noises. We found that long-time exposure to noise significantly affects the individual's performance and psychomotor speed, which resulted in impaired concentration, poor working performance, and increased mistakes at work. This study revealed the relationship between smoking and brain functions in terms of response type and decision-making.

\section{Introduction}

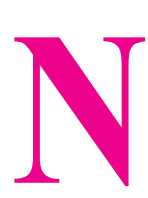

oise is one of the most important sources of stress in life. Loud noise may not only cause physical problems such as hearing loss and increased vulnerability, but also lowers cognitive performance (Alimohammadi, Sandrock, \& Gohari, 2013; Haines, Stansfeld, Job, Berglund, \& Head, 2001; Saremi et al., 2008). Noise is also known as one of the risk factors threatening human health, for example, studies have shown that noise in industrial environments can cause hearing impairment, speech problems, sleep disorders, noise annoyance, and decreased efficiency of individuals (Smith, Kane, \& Popper, 2004; Zaharna \& Guilleminault, 2010; Zare et al., 2009). Adverse effects of exposure to disturbing noises not only affect hearing quality but also harms mental functions that can negatively affect people's living and working conditions (Alimohammadi \& Ebrahimi, 2017).

Because noise is an environmental stressor and combined with other stressors can cause or exacerbate mental disorders and consequently affects individual's performance in certain circumstances (Mendl, 1999), the World Health Organization (WHO) considered incidents as one of the indicators of noise-induced performance deficits. The WHO also regards environmental noise as a direct cause of mental disorders and assumes that noise exacer- bates such ailments as well (Lee, Jerrett, Ross, Coogan, $\&$ Seto, 2014). Noise can directly affect an individual through synaptic nervous interactions and influence his or her emotion, cognition, and perception. In other words, exposure to noise can disrupt homeostasis and mental health (Münzel, Gori, Babisch, \& Basner, 2014).

Sound has different effects on cognitive performances. Research evidence suggests that long-term exposure to noise can affect cognitive performance in central processing and language comprehension (Alimohammadi, Nassiri, Azkhosh, \& Hoseini, 2010). Besides, it can harm continuous and visual attention (Haines, Stansfeld, Job, \& Berglund, 1998; Sanz, García, \& García, 1993). Workers exposed to long-time environmental noises have the lower hearing ability, speech ability, and memory (Hygge, Evans, \& Bullinger, 1996). Studies have also shown that individual variability affects people's efficiency, and emotional characteristics of individuals are associated with the effect of noise intensity on task performance (Bunce, MacDonald, \& Hultsch, 2004).

Available studies on noise effects suggest that noise can cause occupational problems and increase the number of mistakes during working, depending on the type of sound and job. Also, meaningful and relevant information that attracts one's attention is more likely to decrease efficiency (Bunce et al., 2004). Cognitive performance and executive functions play a fundamental role 
in skills and planning activities, number of errors, working memory, emotional control, concentration, inhibition, transmission, initiation, and follow-up (Cui, Wu, \& She, 2009; Farhadian, Akbarfahimi, Abharian, Hosseini, \& Shokri, 2017; Haines et al., 2001). As executive functions are mainly managed by the frontal lobe of the brain, these findings support the hypothesis that states "smokers may have defects in their cognitive-executive functions" (Elwood et al., 1999). In this regard, the studies conducted on executive functions and cognitive performances of substance abusers, especially cigarette smokers, showed that nicotine-containing products such as cigarettes can disrupt executive tasks at workplace, where absolute concentration is required (Kalmijn, Van Boxtel, Verschuren, Jolles, \& Launer, 2002; Mortazavi et al., 2010).

Some studies on the effects of noise with different bandwidths on cognitive performance have shown that cognitive impairment is more common in people when they are exposed to the high-intensity than to the moderate-intensity sounds (Smith \& Broadbent, 1985). Consequently, studying the factors that may lead to cognitive impairment is of great importance (Wright, Peters, Ettinger, Kuipers, \& Kumari, 2016). Few studies have been carried out on the role and impact of using nicotinecontaining products on mental health and sustained attention at workplace. This study aimed to investigate the combined effects of noise and smoking on the cognitive performance of automotive industry workers by using computer-based tests such as Tower of London (TOL), Continuous Performance Test (CPT), and Stroop test.

\section{Methods}

This research is a descriptive-analytical study with a cross-sectional design. 300 workers of the automotive industry in Tehran, Iran were randomly selected and assigned into two groups of noise-exposed (workers under exposure to a noise level of $80-86 \mathrm{dBA} ; \mathrm{n}=150$ ) and nonexposed (workers under exposure to ambient background noise level of 40-50 dBA; $n=150$ ). The demographic information of each group was recorded and checked if they were cigarette smokers. They were considered smokers if they had smoked 5 or more cigarettes a day for 14 years (Wild, Brewster, \& Banerjee, 2005). The sound pressure levels in each group were measured based on an 8-hour equal-loudness contour (formula 1), according to ISO 9612 standard (2009).

We used the Testo CEL 815 sound level meter with a precision of $0.5 \mathrm{~dB}$ and ability to measure the sound intensity in the A network calibrated by Testo IEC 942/90
Class 2 calibrator with an intensity of $114 \mathrm{~dB}$ at the frequency of $1 \mathrm{kHz}$. The subjects who had willingness to continue participation in the study were subjected to psychological and intellectual tests. Their sustained attention was measured using CPT, while for selective attention and cognitive flexibility assessment, the Stroop test was used. Also, their problem-solving ability was assessed using the TOL test. One of the inclusion criteria for entering this study was lacking underlying diseases (heart, pulmonary, and renal diseases) or metabolic and psychiatric disorders. The subjects were allowed to enter the study based on their medical records and demographic information.

1. $\mathrm{L}_{\mathrm{Epd}}(\mathrm{dB})=10 \log \left[\frac{1}{8} \sum_{1}^{1} \mathrm{t}_{\mathrm{i}} 10^{\text {SPL } 10}\right]$

\subsection{Continuous Performance test}

CPT is one of the simplest psychological tests (Halperin, Sharma, Greenblatt, \& Schwartz, 1991). In all forms of this test, subjects must focus on a relatively simple visual or auditory stimulus over a period of time (only a visual stimulus was provided in this study) and present their responses by pressing a button whenever the target stimulus appeared. The goal is that the subjects use their maximum ability and perform the best performance as fast as possible. In this test, there are 150 numbers or images as stimuli, of which $20 \%$ are the target stimuli and the rest $(80 \%)$ the non-target ones. The stimulus was presented for $200 \mathrm{~ms}$, and the interval between the two stimuli was 1 $\mathrm{s}$. The test was conducted after recording the demographic information of participants. Before the test, a training trial was carried out. At the beginning of the training trial, the examiner presented necessary explanations on the screen and fully described them. The duration of the test, including the training trial, was $200 \mathrm{~s}$. For measuring the sustained attention of the participants, their correct responses, errors, omission errors, reaction time, and response time interference were recorded (Warm, 1984; Zarghi \& Zarindast, 2011). The validity of this test ranges from 0.8 to 0.91 (Lezak, Howieson, Loring, \& Fischer, 2004).

\subsection{Stroop test}

The Stroop test evaluates the selective attention and cognitive flexibility in various clinical groups (Stroop, 1992). The test includes two stages. First, the subject is asked to name the color of the word (written in red, blue, yellow, and green). This stage trains to identify the colors and placement of keys on the keyboard and does not affect the final result. At the second stage, a total of 96 
congruent and incongruent color words are shown randomly and sequentially (Figure 1). This test measures mental flexibility, interference, and response inhibition (Wecker, Kramer, Wisniewski, Delis, \& Kaplan, 2000). The interference rate is obtained by subtracting the score of correct responses to incongruent words from that of the congruent ones. Various studies have reported the validity of 0.83 for this test (Lange et al., 1992).

\subsection{Tower of London test}

The TOL test evaluates at least two executive functionings of planning and problem-solving. It is used to assess executive functions and cognitive performance of various people, including the patients with glioma, schizophrenia, and so on (Lange et al., 1992; Sturm, Fernell, \& Gillberg, 2004). During the test, a picture was completed by moving the colored pages (green, blue, and red) to their right locations with a minimum number of moves. It should be noted that only the part B pages could be moved. There were three colored pages in the long column, two in the medium column, and one in the short column. The subject was allowed to solve the problem in three attempts and with a minimum number of moves according to the instructions. After success in each attempt (or if the problem was still unsolved after three attempts), the subject was asked to solve the next puzzle (Figure 2 ). The measured variables in this test were test duration, time delay, total time, result, error, response time, and response interference. The reliability of this test has been reported 0.79 in various studies (Lezak et al., 2004).

\subsection{Data analysis}

For analyzing the collected data, descriptive statistics (frequency, mean, and standard deviation) were used as well as the Kolmogorov-Smirnov test whose results showed the normality of the quantitative data distribution $(\mathrm{P}>0.05)$. tow-way Analysis of Variance (ANOVA) examined the combined effects of noise and smoking. The data were analyzed in SPSS V. 22 by considering the significance level of $\mathrm{P}<0.05$.

\section{Results}

Table 1 presents the demographic characteristics of the participants. Results reported that the Mean \pm SD age of the subjects was $(36.08 \pm 3.64)$ years in the noise-exposed group and (36.19 \pm 3.71$)$ years for the nonexposed group. There was no significant difference between groups in terms of age $(\mathrm{P}=0.789)$. The mean duration of work experiences in nonexposed and noise-exposed groups were 14.94 and 14.99 years, respectively but this difference was not significant $(\mathrm{P}<0.84)$. In terms of educational level, most of the subjects in the two groups had a high school diploma $(\mathrm{n}=113,75 \%)$, and there was a significant relationship between the two groups in terms of their educational level. Regarding marital status, the majority of the subjects were married $(n=140,99 \%)$ and there was no significant relationship between the two groups in terms of marital status (Table 1). The mean

Table 1. Comparing the characteristics of workers in terms of exposure to noise and smoking

\begin{tabular}{|c|c|c|c|c|c|c|}
\hline \multirow{3}{*}{ Variable } & \multicolumn{6}{|c|}{ Mean $\pm S D$} \\
\hline & \multicolumn{3}{|c|}{ Exposed } & \multicolumn{3}{|c|}{ Nonexposed } \\
\hline & Smokers & Non-smokers & Total & Smokers & Non-Smokers & Total \\
\hline Age (y) & $35.80 \pm 3.37$ & $36.30 \pm 3.85$ & $36.08 \pm 3.64$ & $36.61 \pm 3.93$ & $36.02 \pm 3.63$ & $36.19 \pm 3.71$ \\
\hline Work experience (y) & $14.85 \pm 1.92$ & $15.10 \pm 2.12$ & $14.99 \pm 2.03$ & $15.05 \pm 1.92$ & $14.90 \pm 2.12$ & $14.94 \pm 2.06$ \\
\hline Educational level & \multicolumn{6}{|c|}{ No. (\%) } \\
\hline High school diploma & $49(74)$ & $64(76)$ & $113(75)$ & $6(14)$ & $16(15)$ & $22(15)$ \\
\hline Associate degree & $16(24)$ & $15(18)$ & $31(21)$ & $21(47)$ & 39 (37) & $60(40)$ \\
\hline Bachelor's degree and higher & $1(0.02)$ & $5(0.06)$ & $6(0.4)$ & $17(39)$ & $51(48)$ & $68(45)$ \\
\hline \multirow[b]{2}{*}{ Marital status } & $5(0.7)$ & $5(0.6)$ & $10(1)$ & $7(16)$ & $10(1)$ & $17(11)$ \\
\hline & & & & & & \\
\hline Married & 61 (99.3) & 79 (94) & 140 (99) & $37(84)$ & $96(90)$ & 133 (89) \\
\hline
\end{tabular}


Table 2. Mean $\pm S D$ of TOL test variables in terms of exposure to noise and smoking in samples

\begin{tabular}{|c|c|c|c|c|c|c|}
\hline \multirow{3}{*}{$\begin{array}{l}\text { Cognitive Performance } \\
\text { Indicators }\end{array}$} & \multicolumn{6}{|c|}{ Mean $\pm S D$} \\
\hline & \multicolumn{3}{|c|}{ Exposed } & \multicolumn{3}{|c|}{ Nonexposed } \\
\hline & Smokers & Non-Smokers & Total & Smokers & Non-Smokers & Total \\
\hline Test time (s) & $181.29 \pm 99.281$ & $160.92 \pm 94.92$ & $169.88 \pm 97.06$ & $62.86 \pm 13.45$ & $61.66 \pm 15.06$ & $62.01 \pm 14.57$ \\
\hline Test delay (s) & $69.80 \pm 33.58$ & $67.61 \pm 30.21$ & $68.57 \pm 31.64$ & $30.14 \pm 11.52$ & $29.90 \pm 13.48$ & $29.97 \pm 12.90$ \\
\hline Total time (s) & $251.09 \pm 120.27$ & $228.52 \pm 103.81$ & $238.45 \pm 111.53$ & $93.00 \pm 24.87$ & $91.56 \pm 28.42$ & $91.98 \pm 27.35$ \\
\hline Number of errors & $6.39 \pm 2.57$ & $6.26 \pm 2.68$ & $6.32 \pm 2.62$ & $3.52 \pm 1.63$ & $3.63 \pm 2.07$ & $3.60 \pm 1.94$ \\
\hline Test score & $27.77 \pm 3.62$ & $26.51 \pm 3.09$ & $27.07 \pm 3.38$ & $32.59 \pm 2.02$ & $31.92 \pm 2.00$ & $32.12 \pm 2.03$ \\
\hline
\end{tabular}

and standard deviation of TOL, Stroop, and CPT scores are presented in tables 2 to 4 .

The tow-way ANOVA was used to determine the effect of noise and smoking on the cognitive performance variables. The results showed that the combined effect of noise and smoking on the cognitive performance variables was not significant ( $\mathrm{P}>0.345$ ) (Table 2). Regarding their effect on the TOL test variables, ANOVA results showed that smoking had no significant impact on these variables $(\mathrm{P}>0.09)$, but noise significantly affected all 5 variables in the TOL test $(\mathrm{P}<0.001)$ (Table 2$)$. Regarding their effect on 12 variables in the Stroop test, ANOVA results showed that both noise $(\mathrm{P}<0.001)$ and smoking $(\mathrm{P}=0.008)$ significantly affected the mean number of errors (for congruent words) but only noise affected the other 11 variables $(\mathrm{P}<0.001)$ (Table 3$)$.

The study of the combined effects of noise and smoking on 12 CPT variables using the 2-way, ANOVA

Table 3. Mean $\pm S D$ of the Stroop test variables in terms of exposure to noise and smoking in samples

\begin{tabular}{|c|c|c|c|c|c|c|c|}
\hline \multirow{3}{*}{\multicolumn{2}{|c|}{$\begin{array}{c}\text { Cognitive Performance } \\
\text { Indicators }\end{array}$}} & \multicolumn{6}{|c|}{ Mean \pm SD } \\
\hline & & \multicolumn{3}{|c|}{ Exposed } & \multicolumn{3}{|c|}{ Nonexposed } \\
\hline & & Smokers & Non-Smokers & Total & Smokers & Non-Smoking & Total \\
\hline \multirow{5}{*}{ 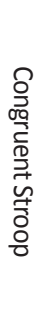 } & Test duration (s) & $56.80 \pm 7.91$ & $58.00 \pm 7.20$ & $57.47 \pm 7.52$ & $44.20 \pm 8.02$ & $44.71 \pm 8 . .30$ & $44.56 \pm 8.19$ \\
\hline & Number of errors & $6.65 \pm 2.33$ & $7.57 \pm 2.15$ & $7.17 \pm 2.27$ & $5.07 \pm 2.19$ & $5.65 \pm 2.43$ & $5.48 \pm 2.37$ \\
\hline & $\begin{array}{l}\text { Number of un- } \\
\text { responded items }\end{array}$ & $1.41 \pm 0.49$ & $1.50 \pm 0.5$ & $1.46 \pm 0.5$ & $0.41 \pm 0.4$ & $0.48 \pm 0.5$ & $0.46 \pm 0.5$ \\
\hline & $\begin{array}{l}\text { Number of correct } \\
\text { responses }\end{array}$ & $39.94 \pm 2.40$ & $38.93 \pm 2.26$ & $39.37 \pm 2.37$ & $42.52 \pm 2.28$ & $41.87 \pm 2.38$ & $42.06 \pm 2.36$ \\
\hline & Response time (ms) & $1238.11 \pm 74.53$ & $1234.42 \pm 76.31$ & $1236.04 \pm 75.30$ & $882.30 \pm 51.14$ & $873.21 \pm 15.24$ & $875.87 \pm 30.59$ \\
\hline \multirow{7}{*}{ 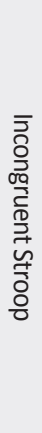 } & Test duration (s) & $66.19 \pm 5.53$ & $66.70 \pm 5.41$ & $66.46 \pm 5.45$ & $53.05 \pm 5.45$ & $51.04 \pm 5.21$ & $51.63 \pm 5.34$ \\
\hline & Number of errors & $9.42 \pm 3.29$ & $9.38 \pm 2.46$ & $9.40 \pm 2.85$ & $5.93 \pm 2.11$ & $6.07 \pm 2.27$ & $6.03 \pm 2.22$ \\
\hline & $\begin{array}{l}\text { Number of un- } \\
\text { responded items }\end{array}$ & $2.52 \pm 0.5$ & $2.49 \pm 0.5$ & $2.50 \pm 0.5$ & $1.52 \pm 0.5$ & $1.49 \pm 0.5$ & $1.50 \pm 0.5$ \\
\hline & $\begin{array}{l}\text { Number of correct } \\
\text { responses }\end{array}$ & $36.06 \pm 3.32$ & $36.13 \pm 2.42$ & $36.10 \pm 2.88$ & $40.55 \pm 2.36$ & $40.44 \pm 2.43$ & $40.47 \pm 2.41$ \\
\hline & Response time (ms) & $1428.02 \pm 57.46$ & $1417.50 \pm 73.01$ & $1422.13 \pm 66.61$ & $935.34 \pm 56.53$ & $924.74 \pm 30.14$ & $927.85 \pm 39.82$ \\
\hline & Interference score & $4.39 \pm 2.39$ & $3.60 \pm 2.25$ & $3.95 \pm 2.34$ & $2.32 \pm 1.37$ & $2.47 \pm 1.69$ & $2.43 \pm 1.60$ \\
\hline & Interference time (s) & $189.91 \pm 94.25$ & $183.08 \pm 96.06$ & $186.09 \pm 95.01$ & $53.05 \pm 14.39$ & $51.53 \pm 14.92$ & $51.97 \pm 14.74$ \\
\hline
\end{tabular}


Table 4. Mean \pm SD of CPT variables in terms of exposure to noise and smoking in samples

\begin{tabular}{|c|c|c|c|c|c|c|c|}
\hline & & & & Mea & $\mathrm{n} \pm \mathrm{SD}$ & & \\
\hline & nnitive Performance & & Exposed & & & Nonexposed & \\
\hline & & Smokers & $\begin{array}{l}\text { Non-Smok- } \\
\text { ers }\end{array}$ & Total & Smokers & Non-Smokers & Total \\
\hline & Number of errors & $3.52 \pm 1.57$ & $3.42 \pm 1.63$ & $3.46 \pm 1.60$ & $2.75 \pm 1.95$ & $2.75 \pm 1.73$ & $2.75 \pm 1.79$ \\
\hline 离 & $\begin{array}{l}\text { Number of un-respond- } \\
\text { ed items }\end{array}$ & $4.61 \pm 2.27$ & $5.08 \pm 2.00$ & $4.87 \pm 2.13$ & $2.45 \pm 2.21$ & $2.15 \pm 1.73$ & $2.24 \pm 1.88$ \\
\hline 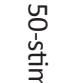 & $\begin{array}{l}\text { Number of correct } \\
\text { responses }\end{array}$ & $41.73 \pm 3.27$ & $41.38 \pm 3.15$ & $41.53 \pm 3.20$ & $44.07 \pm 3.48$ & $44.68 \pm 3.15$ & $44.50 \pm 3.25$ \\
\hline$\underset{\mathscr{D}}{\stackrel{\square}{+}}$ & Response time (ms) & $435.11 \pm 68.61$ & $436.89 \pm 64.77$ & $436.11 \pm 66.27$ & $388.52 \pm 55.13$ & $399.26 \pm 34.70$ & $396.11 \pm 61.83$ \\
\hline & Number of errors & $8.79 \pm 1.25$ & $7.64 \pm 1.75$ & $8.15 \pm 1.65$ & $3.93 \pm 2.69$ & $2.14 \pm 1.69$ & $2.67 \pm 2.18$ \\
\hline 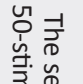 & $\begin{array}{c}\text { Number of } \\
\text { un-responded items }\end{array}$ & $1.64 \pm 0.85$ & $1.60 \pm 0.93$ & $1.61 \pm 0.89$ & $0.82 \pm 1.1$ & $0.59 \pm 0.54$ & $0.66 \pm 0.75$ \\
\hline 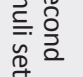 & $\begin{array}{l}\text { Number of correct } \\
\text { responses }\end{array}$ & $39.58 \pm 1.26$ & $40.76 \pm 1.93$ & $40.24 \pm 1.77$ & $45.27 \pm 3.02$ & $47.26 \pm 1.88$ & $46.68 \pm 2.44$ \\
\hline & Response time (ms) & $542.00 \pm 27.93$ & $531.19 \pm 53.15$ & $535.95 \pm 44.08$ & $428.68 \pm 35.66$ & $427.82 \pm 25.11$ & $428.07 \pm 28.49$ \\
\hline & Number of errors & $3.91 \pm 1.54$ & $3.10 \pm 1.55$ & $3.45 \pm 1.59$ & $3.80 \pm 2.44$ & $2.18 \pm 1.44$ & $2.65 \pm 1.93$ \\
\hline 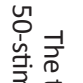 & $\begin{array}{l}\text { Number of un-respond- } \\
\text { ed items }\end{array}$ & $4.73 \pm 2.40$ & $4.90 \pm 1.96$ & $4.83 \pm 2.16$ & $2.20 \pm 2.56$ & $1.20 \pm 1.73$ & $1.49 \pm 2.05$ \\
\hline 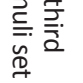 & $\begin{array}{l}\text { Number of correct } \\
\text { responses }\end{array}$ & $41.06 \pm 3.33$ & $42.00 \pm 3.06$ & $41.59 \pm 3.21$ & $44.02 \pm 3.8$ & $46.53 \pm 2.88$ & $45.79 \pm 3.37$ \\
\hline & Response time (ms) & $549.15 \pm 50.08$ & $529.38 \pm 82.45$ & $538.08 \pm 70.55$ & $425.05 \pm 41.39$ & $428.08 \pm 37.60$ & $427.19 \pm 38.63$ \\
\hline
\end{tabular}

indicated that both sound and smoking factors had significant effects on the number of errors and correct responses $(\mathrm{P}<0.001)$.

\section{Discussion}

The results of this study showed the combined effects of noise and smoking on the cognitive performance of workers in the automotive industry. The results of this study not only confirmed the impact of noise on cognitive performance but also emphasized the effect of noise on responsiveness and individual performance speed, which was considerably reduced in exposure to high levels of noise. This finding is in line with the results of the previous studies (Alimohammadi \& Ebrahimi, 2017; Liu, Lin, Huang, \& Chen, 2017). The environmental and acoustic factors remarkably control the speed of individual performance and cognitive process in decisionmaking influenced by psychomotor function (Staal,

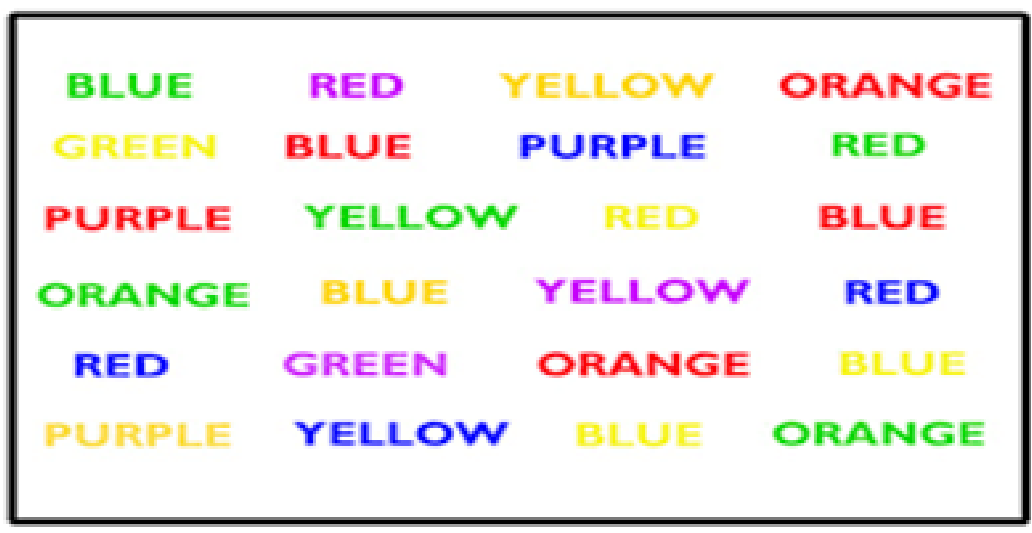

Figure 1. Stroop test 

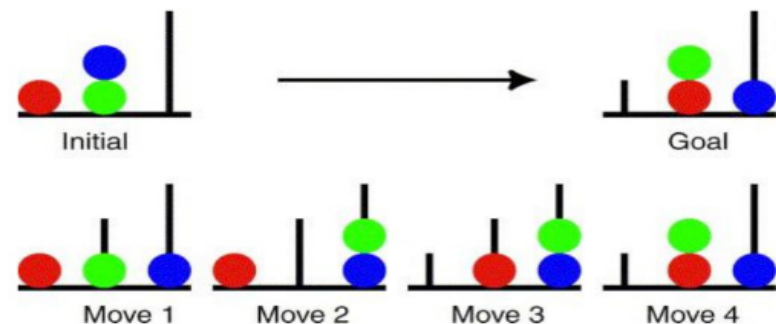

Figure 2. Tower of London test

2004). Various studies on cognitive performance also reported different results. For example, (Alimohammadi et al., 2013) reported no significant relationship between exposure to low-frequency sound (50-70 dBA) and mental performance and concluded that the extraversion and introversion personality traits could increase accuracy and decrease the duration of mental performance. The results of other studies indicated the effect of high- and low-frequency sounds on the cognitive performance of people at the workplace (Alimohammadi et al., 2013; Liu et al., 2017; Waye et al., 2002).

Regarding the effects of smoking on the cognitive performance of the workers in the automotive industry, the results of our study demonstrated the relationship between smoking and cognitive performance. Although brain function and mental performance in the work environment are affected by environmental factors such as light, sound, and temperature, some studies also investigated the effect of using nicotine-containing products such as cigarettes on the mental and brain functions in different age groups and genders and reported various results (Ernst et al., 2001; Kalmijn et al., 2002). Smoking cigarettes and other nicotine-containing products are associated with reduced mental performance as demonstrated by the CPT method in this study, and there is a strong dose-response relationship between smoking rate and mental function (Berkman et al., 1993). Smoking is a strong risk factor that can cause mental and cognitive problems such as dementia in the long term (Carmelli, Swan, Reed, Schellenberg, \& Christian, 1999). Hence, avoiding these risk factors that affect people in the middle age or in various social situations that need higher brain functioning (e.g. at the workplace), can help prevent such damages in the old age (Deary et al., 2003).

The concentration which can affect an individual's reaction time was one of the factors examined in this study in smokers and non-smokers. Smoking interfered with concentration through physiological responses to the nicotine substance in the body and significantly increased the reaction time and the correct response time in Stroop and CPT-tests. In responding to the congruent stimuli in the Stroop test, smokers showed weaker concentration compared with their responses to the incongruent stimuli, implying that concentration affects the time of response to the two different stimuli patterns.

Brain function and mental performance are affected by psychomotor speed and mental flexibility following damage or injury in the cerebral cortex capillaries; therefore, cigarette smoking can cause some changes in the vascular mechanism for blood flow and some physiological changes in the organs like brain (Mortazavi et al., 2010; Newhouse, Potter, \& Singh, 2004). Thus, the smoking mechanism in patients with stroke and dementia has been well-defined through the effect of smoking on the vascular system (Cees De Groot et al., 2000; Raininko \& Tilvis, 1993; Rogers, Meyer, Judd, \& Mortel, 1985; Terborg, Bramer, Weiller, \& Röther, 2002).

According to the study of (Kalmijn et al., 2002) on the effects of cigarette smoking on cognitive performance, the psychomotor speed and cognitive flexibility were significantly lower in smokers compared with nonsmokers, indicating the physiological effects of nicotine on the cortical vascular system. This finding is consistent with our study finding regarding the reduced speed of cognitive functioning. Considering this vascular cognitive mechanism, the smokers in our study had different cognitive flexibility and psychomotor speed due to the effect of nicotine, which can interfere with concentration and result in poor working performance, as well as increased occupational errors and lack of timely decisionmaking. In this study, the number of correct responses and the response time to the test questions pointed out that psychomotor speed in smokers was reduced due to exposure to nicotine.

Altogether, cigarette smoking has a direct impact on workers' cognitive functioning and reduce their mental and cognitive performance. Smokers also suffered more from concentration deficits and poor working performance compared with non-smokers. According to the results of the Stroop test and CPT-test, smokers had 
low-speed cognitive processing in decision making and weakness in making timely decisions.

The diagnostic skill model is one of the main reasons why concentration is more affected than attention (Alimohammadi \& Ebrahimi, 2017). According to this model, attention is a less sensitive skill. This study also examined the effect of concentration on the reaction time of groups with and without exposure to noise. Exposure to noise could significantly increase the reaction and correct response time during Stroop, TOL, and CPT-tests by interfering with concentration. In the Stroop test, exposure to noise reduced concentration in responding to the incongruent stimuli more compared to the responses to congruent stimuli, implying the effect of concentration on the time of responding to the two different stimuli patterns.

The rate of human errors in high-risk and managerial jobs, where there is a need for proper concentration, has a relationship with exposure to noise such that with higher noise frequency, the human error rate increases (Ljungberg, Neely, \& Lundström, 2004). This finding is consistent with our study, which showed that the workers' more exposure to noise was associated with their increased number of errors. Previous studies have examined various factors related to the impact of noise on the cognitive performance of people, including noise characteristics and job complexity and difficulty (Staal, 2004). Generally, chronic exposure to noise significantly affects an individual's performance and psychomotor speed, which results in impaired concentration, poor working performance and increased mistakes at work. In this study, the number of wrong and correct answers in the conducted tests confirmed that psychomotor function is disrupted after exposure to noise.

Based on the transactional model of stress, mental assessment of threatening events, or the ability to cope with stressors are related to the mental stress experienced by individuals (Stokes \& Kite, 2001). Although the findings of this study can be affected by the subjective evaluation of individuals, cognitive assessment of stressors had a direct impact on the cognitive performance of workers such that positive assessments led to increased cognitive performance, and negative assessments led to decreased cognitive performance (Staal, 2004). When exposed to noise, the workers in this study had no full knowledge of the stressors affecting their cognitive performance and individual function. Awareness about these stressors (sources of noise pollution) can increase the positive effects of subjective function (e.g. following healthy be- haviors), and they can work better in those settings with a control approach.

Experiencing stressful events that do not threaten their lives can also bring up positive emotions on them (e.g. lack of mental disorder) and increase the workers' selfconfidence at the workplace. In addition, studies have emphasized that the Stroop test and other cognitive/ psychological tests are beneficial for the analysis of mental performance and responses to intervening stimuli that require attention (e.g. low- or high-frequency noises), and making it possible to examine the impacts on cognitive performance. The results of this study were partly consistent with the central nervous system arousal theory which is related to the stimulation of the central nervous system and the adaptation of human responses to stimuli. In our study, the samples' physiological system could adapt to the noise in the long term and could even work better with the noise, but its consequences would reduce their accuracy and concentration in performing the assigned tasks (Mehri, Alimohammadi, Ebrahimi, Hajizadeh, \& Roudbari, 2018).

In general, the reaction time in mental activities is influenced by noise. Various studies reported the effect of exposure to high- and low-frequency noises on cognitive performance. These reports indicate the influence of exposure to chronic noise on the mental and psychological conditions, including performance and processing speed. Several studies that have examined the relationship of human cognitive performance with other physical factors have also reported similar results (Haines et al., 1998; Losier, McGrath, \& Klein, 1996; Sanz et al., 1993). Sound pressure levels above $65 \mathrm{~dB}$ can potentially affect the cognitive performance and other nonauditory functions, increase the risk of different human errors at work where people long exposed to loud noises, and cause cognitive impairment (delayed reaction time, poor attention, etc.).

In this study, the TOL test indicated a significant relationship between individual performance and strategic approaches to problem-solving and planning and noise exposure. Variables such as time delay and the number of errors showed a significant and robust relationship with noise exposure such that those exposed to chronic noise had more delays and errors in responding to this test. Mental and cognitive performances of the workers employed in industries are directly and significantly related to chronic exposure to noise. Controlling noise in industries and using personal protective equipment can remarkably and significantly reduce human errors and, on the other hand, increase efficiency and effectiveness 
to achieve organizational goals (Golmohammadi, Giahi, Aliabadi, \& Darvishi, 2014; Malchaire, 2000).

One of the limitations of this study was the lack of individual matching, which can allow a more accurate evaluation of the study variables and eliminate the effect of confounders. Another limitation was the theoretical aspect of the issue. In this regard, the test stimuli were presented to the subjects on a computer monitor, which may not adequately examine the cognitive factors.

Noise exposure and smoking could affect the workers' cognitive performance, thereby reducing their attention and concentration and increasing the risk of errors at work. Hence, taking into account the effect of noise and smoking on workers' health, developing strategies for controlling smoking, and reducing noise pollution should be considered among the essential preventive measures.

\section{Ethical Considerations}

\section{Compliance with ethical guidelines}

All of the experiments were conducted according to the guidelines of the Ethics Committee of Iran University of Medical Sciences (Ethical code: IR.IUMS. REC1395.9411139003).

\section{Funding}

This research was financially supported by Iran University of Medical Sciences.

\section{Authors' contributions}

Conceptualization: Iraj Alimohammadi and Fakhradin Ahmadi Kanrash; Methodology: Fakhradin Ahmadi Kanrash, Jamileh Abolghasemi and Kazem Rahmani; Investigation: Fakhradin Ahmadi Kanrash and Hanieh Afrazandehh; Supervision: Iraj Alimohammadi; Writing-original draft, writing-review \& editing, funding acquisition, resources, reviewing the manuscript and approving the final version for publication: All authors.

\section{Conflict of interest}

The authors declare no potential conflict of interest.

\section{Acknowledgments}

The authors would like to thank the Vice Chancellor for Research of Iran University of Medical Sciences and the car factory in Tehran for their cooperation in conducting this study.

\section{References}

Alimohammadi, I., \& Ebrahimi, H. (2017). Comparison between effects of low and high frequency noise on mental performance. Applied Acoustics, 126, 131-5. [DOI:10.1016/j.apaa coust.2017.05.021]

Alimohammadi, I., Nassiri, P., Azkhosh, M., \& Hoseini, M. (2010). Factors affecting road traffic noise annoyance among white-collar employees working in Tehran. Journal of Environmental Health Science \& Engineering, 7(1), 25-34.

Alimohammadi, I., Sandrock, S., \& Gohari, M. R. (2013). The effects of low frequency noise on mental performance and annoyance. Environmental Monitoring and Assessment, 185(8) 7043-51. [DOI:10.1007/s10661-013-3084-8] [PMID]

Berkman, L. F., Seeman, T. E., Albert, M., Blazer, D., Kahn, R., \& Mohs, R., et al. (1993). High, usual and impaired functioning in community-dwelling older men and women: Findings from the MacArthur foundation research network on successful aging. Journal of Clinical Epidemiology, 46(10), 1129-40. [DOI:10.1016/0895-4356(93)90112-E]

Bunce, D., MacDonald, S. W., \& Hultsch, D. F. (2004). Inconsistency in serial choice decision and motor reaction times dissociate in younger and older adults. Brain and Cognition, 56(3), 320-7. [DOI:10.1016/j.bandc.2004.08.006] [PMID]

Carmelli, D., Swan, G. E., Reed, T., Schellenberg, G., \& Christian, J. C. (1999). The effect of apolipoprotein E $\varepsilon 4$ in the relationships of smoking and drinking to cognitive function. Neuroepidemiology, 18(3), 125-33. [DOI:10.1159/000026204] [PMID]

Cees De Groot, J., De Leeuw, F. E., Oudkerk, M., Van Gijn, J. Hofman, A., Jolles, J., et al. (2000). Cerebral white matter lesions and cognitive function: The rotterdam scan study. Annals of Neurology, 47(2), 145-51. [DOI:10.1002/15318249(200002)47:23.0.CO;2-P]

Cui, B., Wu, M., \& She, X. (2009). Effects of chronic noise exposure on spatial learning and memory of rats in relation to neurotransmitters and NMDAR2B alteration in the hippocampus. Journal of Occupational Health, 51(2), 152-8. [DOI:10.1539/ joh.L8084] [PMID]

Deary, I. J., Pattie, A., Taylor, M., Whiteman, M. C., Starr, J. M., \& Whalley, L. J. (2003). Smoking and cognitive change from age 11 to age 80. Journal of Neurology, Neurosurgery \& Psychiatry 74(7), 1006-7. [DOI:10.1136/jnnp.74.7.1006] [PMID] [PMCID]

Elwood, P., Gallacher, J., Hopkinson, C. A., Pickering, J., Rabbitt, P., Stollery, B., et al. (1999). Smoking, drinking, and other life style factors and cognitive function in men in the Caerphilly cohort. Journal of Epidemiology \& Community Health, 53(1), 9-14. [DOI:10.1136/jech.53.1.9] [PMID] [PMCID]

Ernst, M., Matochik, J. A., Heishman, S. J., Van Horn, J. D., Jons, P. H., Henningfield, J. E., et al. (2001). Effect of nicotine on brain activation during performance of a working memory task. Proceedings of the National Academy of Sciences, 98(8), 4728-33. [DOI:10.1073/pnas.061369098] [PMID] [PMCID] 
Farhadian, M., Akbarfahimi, M., Abharian, P. H., Hosseini, S. G., \& Shokri, S. (2017). Assessment of executive functions in methamphetamine-addicted individuals: Emphasis on duration of addiction and abstinence. Basic and Clinical Neuroscience, 8(2), 147-54. [DOI:10.18869/nirp.bcn.8.2.147] [PMID] [PMCID]

Golmohammadi, R., Giahi, O., Aliabadi, M., \& Darvishi, E. (2014). An intervention for noise control of blast furnace in steel industry. Journal of Research in Health Sciences, 14(4), 28790. [PMID]

Haines, M. M., Stansfeld, S. A., Job, R. F. S., \& Berglund, B. (1998). Chronic aircraft noise exposure and child cognitive performance and stress. Proceedings of the $7^{\text {th }}$ International Conference on Noise as a Public Health Problem, 1, 329-35.

Haines, M. M., Stansfeld, S. A., Job, R. S., Berglund, B., \& Head, J. (2001). Chronic aircraft noise exposure, stress responses, mental health and cognitive performance in school children. Psychological Medicine, 31(2), 265-77. [DOI:10.1017/ S0033291701003282] [PMID]

Halperin, J. M., Sharma, V., Greenblatt, E., \& Schwartz, S. T. (1991). Assessment of the continuous performance test: reliability and validity in a nonreferred sample. Psychological Assessment, 3(4), 603-8. [DOI:10.1037/1040-3590.3.4.603]

Hygge, S. (1996). The Munich Airport noise study-cognitive effects on children from before to after the change over of airports. Proceedings Inter-noise, 96(1), 2189-92.

International Organization for Standardization. (2009). 9612: Acoustics-determination of occupational noise exposure-Engineering method (ISO Standard No. 9612). Retrieved from: https://www.iso.org/standard/41718.html

Kalmijn, S., Van Boxtel, M. P., Verschuren, M. W., Jolles, J., \& Launer, L. J. (2002). Cigarette smoking and alcohol consumption in relation to cognitive performance in middle age. American Journal of Epidemiology, 156(10), 936-44. [DOI:10.1093/aje/ kwf135] [PMID]

Lange, K. W., Robbins, T., Marsden, C., James, M., Owen, A., \& Paul, G. (1992). L-dopa withdrawal in Parkinson's disease selectively impairs cognitive performance in tests sensitive to frontal lobe dysfunction. Psychopharmacology, 107(2-3), 394-404. [DOI:10.1007/BF02245167]

Lee, E. Y., Jerrett, M., Ross, Z., Coogan, P. F., \& Seto, E. Y. (2014). Assessment of traffic-related noise in three cities in the United States. Environmental Research, 132, 182-9. [DOI:10.1016/j.enn vres.2014.03.005] [PMID] [PMCID]

Lezak, M. D., Howieson, D. B., Loring, D. W., \& Fischer, J. S (2004). Neuropsychological assessment. Oxford: Oxford University Press.

Liu, T., Lin, C. C., Huang, K. C., \& Chen, Y. C. (2017). Effects of noise type, noise intensity, and illumination intensity on reading performance. Applied Acoustics, 120, 70-4. [DOI:10.1016/j. apacoust.2017.01.019]

Ljungberg, J., Neely, G., \& Lundström, R. (2004). Cognitive performance and subjective experience during combined exposures to whole-body vibration and noise. International Archives of Occupational and Environmental Health, 77(3), 217-21. [DOI:10.1007/s00420-003-0497-7] [PMID]
Losier, B. J., McGrath, P. J., \& Klein, R. M. (1996). Error patterns on the continuous performance test in non $\square$ medicated and medicated samples of children with and without ADHD: A meta $\square$ analytic review. Journal of Child Psychology and Psychiatry, 37(8), 971-87. [DOI:10.1111/j.1469-7610.1996.tb01494.x] [PMID]

Malchaire, J. (2000). Strategy for prevention and control of the risks due to noise. Occupational and Environmental Medicine, 57(6), 361-9. [DOI:10.1136/oem.57.6.361] [PMID] [PMCID]

Mehri, A., Alimohammadi, I., Ebrahimi, H., Hajizadeh, R., \& Roudbari, M. (2018). Effect of traffic noise on mental performance with regard to introversion and task complexity. Applied Acoustics, 132, 118-23. [DOI:10.1016/j.apaa coust.2017.11.019]

Mendl, M. (1999). Performing under pressure: stress and cognitive function. Applied Animal Behaviour Science, 65(3), 221-44. [DOI:10.1016/S0168-1591(99)00088-X]

Mortazavi, S., Kashani, M. M., Khavanin, A., Alameh, A., Mirzaee, R., \& Akbari, M. (2010). Effects of N-Acetylcysteine on auditory brainstem response threshold shift in rabbits exposed to noise and carbon monoxide. American Journal of Applied Sciences, 7(2), 201. [DOI:10.3844/ajassp.2010.201.207]

Münzel, T., Gori, T., Babisch, W., \& Basner, M. (2014). Cardiovascular effects of environmental noise exposure. European Heart Journal, 35(13), 829-36. [DOI:10.1093/eurheartj/ehu030] [PMID] [PMCID]

Newhouse, P. A., Potter, A., \& Singh, A. (2004). Effects of nicotinic stimulation on cognitive performance. Current Opinion in Pharmacology, 4(1), 36-46. [DOI:10.1016/j.coph.2003.11.001] [PMID]

Rogers, R. L., Meyer, J. S., Judd, B. W., \& Mortel, K. F. (1985). Abstention from cigarette smoking improves cerebral perfusion among elderly chronic smokers. JAMA, 253(20), 2970-4. [DOI:10.1001/jama.253.20.2970] [PMID]

Sanz, S. A., García, A. M., \& García, A. (1993). Road traffic noise around schools: A risk for pupil's performance? International Archives of Occupational and Environmental Health, 65(3), 205-7. [DOI:10.1007/BF00381157] [PMID]

Saremi, M., Rohmer, O., Burgmeier, A., Bonnefond, A., Muzet, A., \& Tassi, P. (2008). Combined effects of noise and shift work on fatigue as a function of age. International Journal of Occupational Safety and Ergonomics, 14(4), 387-94. [DOI:10.1080 /10803548.2008.11076779] [PMID]

Smith, A. P., \& Broadbent, D. E. (1985). The effects of noise on the naming of colours and reading of colour names. Acta Psychologica, 58(3), 275-85. [DOI:10.1016/0001-6918(85)90026-5]

Smith, M. E., Kane, A. S., \& Popper, A. N. (2004). Noise-induced stress response and hearing loss in goldfish (Carassius auratus). Journal of Experimental Biology, 207(3), 427-35. [DOI:10.1242/jeb.00755] [PMID]

Staal, M. A. (2004). Stress, cognition, and human performance: A literature review and conceptual framework. California: NASA technical report server.

Stokes, A.F., \& Kite, K. (2001). On grasping a nettle and becoming emotional. In. Hancock, P.A., and Desmond, P.A. (Eds), Stress, workload, and fatigue (pp. 162-81). New Jersry: L. Erlbaum. 
Stroop, J. R. (1992). Studies of interference in serial verbal reactions. Journal of Experimental Psychology: General, 121(1), 15-23. [DOI:10.1037/0096-3445.121.1.15]

Sturm, H., Fernell, E., \& Gillberg, C. (2004). Autism spectrum disorders in children with normal intellectual levels: Associated impairments and subgroups. Developmental Medicine and Child Neurology, 46(7), 444-7. [DOI:10.1111/j.1469-8749.2004. tb00503.x] [PMID]

Terborg, C., Bramer, S., Weiller, C., \& Röther, J. (2002). Short-term effect of cigarette smoking on $\mathrm{CO} 2$-induced vasomotor reactivity in man. Journal of the Neurological Sciences, 205(1), 15-20. [DOI:10.1016/S0022-510X(02)00308-8]

Warm, J. S. (1984). Sustained attention in human performance. Hoboken: John Wiley \& Sons Inc.

Waye, K. P., Bengtsson, J., Rylander, R., Hucklebridge, F., Evans, P., \& Clow, A. (2002). Low frequency noise enhances cortisol among noise sensitive subjects during work performance. Life Sciences, 70(7), 745-58. [DOI:10.1016/S0024-3205(01)01450-3]

Wecker, N. S., Kramer, J. H., Wisniewski, A., Delis, D. C., \& Kaplan, E. (2000). Age effects on executive ability. Neuropsychology, 14(3), 409-14. [DOI:10.1037/0894-4105.14.3.409] [PMID]

Wild, D., Brewster, M., \& Banerjee, A. (2005). Noise $\square$ induced hearing loss is exacerbated by long $\square$ term smoking. Clinical Otolaryngology, 30(6), 517-20. [DOI:10.1111/j.17494486.2005.01105.x] [PMID]

Wright, B., Peters, E., Ettinger, U., Kuipers, E., \& Kumari, V. (2016). Effects of environmental noise on cognitive (dys) functions in schizophrenia: A pilot within-subjects experimental study. Schizophrenia Research, 173(1), 101-8. [DOI:10.1016/j. schres.2016.03.017] [PMID] [PMCID]

Ylikoski, R., Ylikoski, A., Erkinjuntti, T., Sulkava, R., Raininko, R., \& Tilvis, R. (1993). White matter changes in healthy elderly persons correlate with attention and speed of mental processing. Archives of Neurology, 50(8), 818-24. [DOI:10.1001/arch neur.1993.00540080029009] [PMID]

Zaharna, M., \& Guilleminault, C. (2010). Sleep, noise and health Noise and Health, 12(47), 64-9. [DOI:10.4103/1463-1741.63205] [PMID]

Zare, M., Abedi, K., Rahiminezhad, M., Halvani, G. H., Barkhourdari, A., \& Valipour, E. (2009). Influence of aircraft noise on hypertension in airport staff. Journal of Babol University of Medical Sciences, 6(47), 54-61.

Zarghi, A., \& Zarindast, M. R. (2011). Demographic variables and selective, sustained attention and planning through cognitive tasks among healthy adults. Basic and Clinical Neuroscience, 2(3), 58-67. 
This Page Intentionally Left Blank 